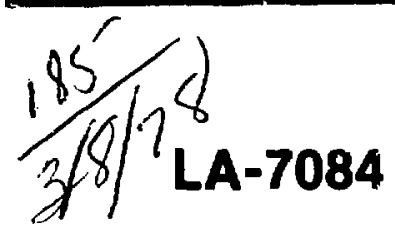

Lh.

UC-4

Issued: February 1978

\title{
Anion Exchange of 58 Elements in Hydrobromic Acid and in Hydriodic Acid
}

\author{
S. F. Marsh \\ J. E. Alarid \\ C. F. Hammond \\ M. J. McLeod \\ F. R. Roensch \\ J. E. Rein
}

1 


\section{ANION EXCHANGE OF 68 ELEMENTS IN HYDROBROMIC ACID AND IN HYDRIODIC ACID}

\author{
by
}

\author{
S. F. Marah, J. E. Alarid, C. F. Hammond, \\ M. J. McLeod, F. K. Roensch, and J. E. Rein
}

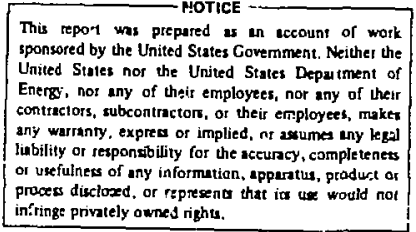

This report was prepared at in tceount of work sponsored by the United States Government. Neither the Stres nor the United States Depa iment of contractors, subeontractor, or their erployees, make any warranty. express or implied, nt asumes eny kgal or urefulnets of any informetion, epperatus, produrt or in?'ringe priviely owned night.

\begin{abstract}
Anion exchange distributions of 68 elements have been measured from 0.1-8.7 $M \mathrm{HBr}$ and from 0.1-7.4M HI onto three strong-base resing, 8 and $4 \%$ cross-linked and macroporous. Data were nbtained by 16- to 18-h dynamic batch contacts. Anion exchange in these media is compared to that in $\mathrm{HCl}$. The effect of regin cross-linkage is considerably greatar in HI media than in HBr and HCl media. Examples are presented of potentially uneful separa" tlons uaing $\mathrm{HBr}$ and $\mathrm{HI}$ media alone and in combination with $\mathrm{HCl}$.
\end{abstract}

\section{INTRODUCTION}

Anion exchange has become an ircreasingly useful chemical separation rechnique since Kraus demonstrated its value using aqueous $\mathrm{HCl}$. The combined strong anion-complexing and reductive properties of $\mathrm{HBr}$ and $\mathrm{HI}$ can be expected to produce unique distributions and serarations.

Distribution data are available for many acqueous media, including $\mathrm{HNO}_{2}$ ' $\mathrm{HF}$; acetic acid," and $\mathrm{H}_{0} \mathrm{PO}_{4}$ " Also available are data for many organic solvents, exemplified by organic acide and mixed aqueous and organic solvents. ${ }^{\top}$ Conspicuously absent are comprehensive anion exchange data from aqueous $\mathrm{HBr}$ and $\mathrm{HI}$ media. No multielement study of $\mathrm{HI}$ media has been published. The only atudy covering a broad range of aqueous $\mathrm{F} / \mathrm{BB}$ concentrations gives data for 15 ions but does not state the concentrations of the ions in contact with the rosin. Although these data generally agree with ours, no basis for valid comparison is considered to exist. Another study provides data for 19 elements over the limited acqueous $\mathrm{HBr}$ range of $0.15-0.9 \mathrm{M}$. The data for all ions except $\operatorname{In}^{2+}$ agree with ours.

In this measurement of distribution from aqueous $\mathrm{HBr}$ and $\mathrm{HI}$ media, we have included the effect of resin cross-linkage by using strnng-base resins of 4 and $8 \%$ cross-linkages, as weil as macroporous resin (MP1). The latter renin, with its open pore structure, is an excellent substitute for conventional microporous resin in arion exchange separations that involve aguenus $\mathrm{HCl}$ media or a mixed methanol and HNO, solvent. ${ }^{\circ}$ In addition to providing fast equilibrium, its use lessens the differing elution properties typical of different batches of microporous resin.

Distribution data for 58 elements in $0.1-8.7 \mathrm{M} \mathrm{HBr}$ and 0.1-7.4M HI are given for each resin. Our major intent is to provide relative distribution data that will lead to practically useful separations. We hope that other investigators' considerations of the differing distributions onto the three resin types will lead 
to better understanding of ion exchange mechanisms.

\section{REAGENTS}

Resin. Dowex resins, 50- to 100-mesh, from Bio-Rad Laboratories were used. Batch designations, provided because of possible batch-to-batch differences, are 12908 ( $A G 1 \times 4$ ), 12618 (AG 1 × 8), and 9881 (AG MP1).

Hydrobromic Acid. AR grade, 47-49\% (8.7M) acid was used. It was diluted with distilled water to 0.1 , 1,3 , and $6 M$ concentrations.

Hydriodic Acid. AR-grade, 57\% (7.4M) acid, without holding reductant, was used. (The usual $\mathrm{H}_{8} \mathrm{PO}_{8}$ preservative and its oxidation products could affect distribution). The acid was diluted with distilled water to $0.1,1,3$, and $5.7 M$ concentrations. Elements and Radioactive Tracers. The distribution data for most elements were obtained using $0.01 \mathrm{M}$ element solutions plus radioactive tracer (see the Experimental section). Metals of $>99 \%$ purity were dissolved directly in $\mathrm{HBr}$ or $\mathrm{HI}$ where feasib!e. Selected compounds, also $>99 \%$ pure, were converted to bromicle or iodide salts without introduction of other potentially interfering anions.

Most radioactive tracers were prepared by thermal neutron activation in the Los Alamos Scientific Laboratory (LASL) Omega West Reactor. Exceptions were ${ }^{\circ 8} \mathrm{Zr}$, ${ }^{\circ} \mathrm{Tc},{ }^{\circ 8} \mathrm{Ge}$, and ${ }^{7} \mathrm{Be}$ obtained commercially, and ${ }^{20} \mathrm{Po}$ and ${ }^{226 \mathrm{Ra}}$ obtained from other LASL projects.

\section{EXPERIMENTAL}

Resin Conversion to Bromide and Iodide Forms and Measurement of Haijde Contents

Hydioaic acid is availsble with or without a holding reductant of $\mathrm{H}_{8} \mathrm{PC}_{2}$. We selected $\mathrm{HI}$ without $\mathrm{H}_{3} \mathrm{PO}_{2}$ to avoid competitive complexes involving oxyphosphorous anions. Without a holding reductant, air cxidation slowly produces elemental iodine which is sorbed on resin. Eilemental iodine also forms during equilibration with ions that oxidize iodide.
The three resins were obtained in the chloride form. To convert the resins to the bromide and iodide forms, several hundred grams of each was washed free of fines and water-soluble components and transferred to a $3.7-\mathrm{cm}$-diam by $50-\mathrm{cm}-\mathrm{long}$ glass column. Then an amount of $\mathrm{HBr}$ or $\mathrm{HT}$ equal to at least six times the theoretical capacity of the resin (based on the meq/g value stated by the supplier) was passed through. Each column was rinsed with water until the effluent $\mathrm{pH}$ increased to 3 . Additional 1-liter volumes of water were passed through until the $\mathrm{pH}$ remained constant. The resin was air-dried in a Buchner funnel and heated at $70^{\circ} \mathrm{C}$ to constant weight. Nearly $100 \mathrm{~h}$ of heating was required.

The dried resin weights could not be correlated wtih the ab-received resin weights, because of their high and undetermined 42-E2\% water contents. Therefore the distribution data are based on dried weights.

The residual chloride content relative to bromide or iodide was determined by thermal neutron activation analysis of each converted, dried resin. The measured $<0.015 \mathrm{Cl} / \mathrm{Br}$ and $\mathrm{Cl} / \mathrm{I}$ mole ratios are considered too low to effect the measured distribution data significantly.

The total bromide and iodide contents were determined by eluting $1 \mathrm{~g}$ of resin with $4 M \mathrm{HClO}_{4}$ and potentiometrically titrating the effluent with $\mathrm{AgNO}_{8}$. Elution (and titration) was repeated to completeness. The measured iodide content per gram of converted resin includes an uncertainty caused by sorption of elemental iodine. The measured contents were $3.5 \pm 0.2 \mathrm{meq}$ of bromide and $3.0 \pm 0.3$ meq of iodide per gram of each resin.

\section{Selection of 0.01M as Element Concentration Level}

The exchange behavior of an ion at very low concentration often differs significantly from that at moderate concentration. Rieman and Walton ${ }^{11}$ explain that exchange between resin and $\leq 0.001 \mathrm{~N}$ solution generally is controlled by film diffusion, whereas at $\sim 0.01 \mathrm{~N}$ concentrations both film and bead diffusion prevail. Kim ${ }^{28}$ reports substantially 
different behavior of some ions with ion exchange resins copolymerized from styrene and $m$ divinylbenzene and from siyrene and $p$ divinylbenzene. Because the resins used are mixtures of $\mathrm{m}$ - and p-divinulbenzene, it seems reasonable that ions at very low concentration would interact preferentially with the most accessible exchange sites, or those capable of enhanced bond stability. For this reason and perhaps others, distributions of ions at very low concentrations do not represent distributions at higher concentrations. Also, distributions at high ion concentrations can differ as saturation of exchange sites is approached. The element solutions in this study were $0.01 \mathrm{M}$, except for lower, tracer-only, levels of ${ }^{\infty} \mathrm{Nb},{ }^{2 ! 0} \mathrm{Po}$, ${ }^{2 m} \mathrm{Ra},{ }^{2 *} \mathrm{~Pa}$, and ${ }^{241} \mathrm{Am}$. Solubilities of some elements ware exceeded at the $0.01 M$ level, especially at the higher acid levels. These exceptions are noted in the Discussion section.

\section{Distribution Measurement Experiment:}

Distributions were measured after 16- to 18 -h batch contacts of $0.25 \mathrm{~g}$ of resin and $2.5 \mathrm{ml}$ of the elnment solution. The 16 - to 18 -h contact period substantially gave equilibrium. It was held constant to permit comparison of sorptions, which can be affected by rate-dependent reactions, by the three resins. Total uptake by the resin of the element in a $0.01 M$ solution was $3-10 \%$ of the resin capacity.

The resin and solution (plus tracer) were placed in 20-ml glass vial3 and shaken mechanically. After the resin had settled, the solution was analyzed for the element relative to an identical solution that had not contacted resin. For experiments with gamma-emitting radiotracers, $1 \mathrm{ml}$ of solution was transferred to a glass vial that was counted using a $\mathrm{NaI}(\mathrm{Tl})$ detector. Beta and alpha radiotracers were measured by counting measured aliquots evaporated on glass or dissolved in solution appropriate for liquid scintillation counting. Multichannel gamma spectrometry was used to resolve gamma-tmitting paient and daughter pairs.

No suitable radiotracers were available for 6 of the 58 elements. Of these, vanadium and rhodium were determined by atomic absorption spec. trophotometry and aluminum, magnesium, calcium, and nickel were determined by chelometric titrinietry.

\section{Data Presentation}

Distribution data generally are expressed in terms of the distribution ratio, $D$, the ion concentration on the resin relative to that in solution at equilibrium, for equal weights of resin and solution. Computation of $D$ from batch experimental data is inexact because the resin phase, even after filtration, contains a significant amount of the aqueous phase. For liquid-liquid extraction equilibrium, Morrison and Freiser $^{10}$ recommend that distribution data be expressed in terms of "percent extraction" for practicality. In their words, "When the extraction efficiency appraaches $100 \%$, the distribution ratio approaches infinity as a limit. Thus, for differences in extraction in the range of 99 to $100 \%$, the distribution ratio will vary from 99 to infinity. Initial observation of such widely differing distribution ratios might erroneously suggest a sprious discrepancy when in reality the extraction would be nearly complete in both instances."

The distribution data are in percentages of ion sorbed on resin. Measurements of the solutions after batch contact are not highly accurate when the ion concentration is either very high or very low. Therefore, reporting batch-contact data in units of distribution coefficient, $\mathrm{Kd}$, can be misleading.

After the 16- to 18-h batch contact of $0.25 \mathrm{~g}$ of resin and $2.5 \mathrm{ml}$ of solution, $1 \mathrm{ml}$ of solution, free of resin particles (termed $S_{\text {pout }}$ ), was measured for element content by radiometric assay or by chemical analysis relative to $1 \mathrm{ml}$ of the identical solution that had not contacced resin (termed $S_{\text {pre }}$ ). The percentage of element sorbed was computed using

$$
\text { per cent on resin }=q s=100 \frac{s_{\text {pre }}-s_{\text {post }}}{S_{\text {pre }}} .
$$

The $0.25 \mathrm{~g}$ of resin and $2.5 \mathrm{ml}$ of sclution provided convenient quantities for measurement. The tenfold ratio of solution to resin gives a lower sorption percentage than would have been measured using equal quantities of resin and solution. Because we wanted 
to show relative ion exchange, we teported the sorption percentages computed using the above relationship, rather than adjusting to an equalvolume basis as was done by Kraus and Nelson." The \% S data can be converted to $\mathrm{Kd}$ values by using

$$
K d=\frac{(\% S)(R)}{100-(\% S)} .
$$

where $\mathbf{R}=10$, the liquid-to-resin ratio of our measurements.

The distr:butions from $\mathrm{HBr}$ solutions are presentea in Figs. 1-3; those from HI solutions, in Figs. 4-6.

\section{DISCUSBION}

The distribution data are considered in periodic groupings, first with $1 \times 8$ resin as a function of the type of halide acid, then as a function of resin crosslinkage. We also discuss how a nunisotopic carrier affects sorption of tracer-level elewents, on the basis of cata from radium with and without barium carrier.

Elements in their usual and stable oxidation states were added to $\mathrm{HBr}$ and $\mathrm{HI}$. The resulting oxidation states are predicted, for discussion, from standard oxidation potentials. ${ }^{14}$

\section{Distribution as a Function of Acid Type}

Distributions of elements from $\mathrm{HBr}$ and $\mathrm{HI}$ are compared with Kraus and Nelson's' ${ }^{1} \mathrm{HCl}$ distribution dista, reproduced as Fig. 7. (We have added a \% $S$ equivalent scale for $R=10$ to the right of the key in Fig. 7 to facilitate comparison with Figs. 1.6).

Alkalies. The alkalies are not sorbed from $\mathrm{HBr}$, $\mathrm{HI}$, or $\mathrm{HCl}$.

Alkaline Earths. Unexpectedly, barium is sorbed onto the resins from strong $\mathrm{HBr}$. Tracer levels of radium are not sorbed from any acid. However, when $0.01 \mathrm{M}$ barium is present as a nonisotopic carrier (shown by broken lines), radium is sorbed from $\mathrm{HBr}$ like barium. This topic is discussed later.
Scandium, Yttrium, and Lanthanides. These trivalent ions are not sorbed from $\mathrm{HBr}, \mathrm{HI}$, or $\mathrm{HCl}$. Tetravalent cerium is reduced by $\mathrm{HBr}$ and $\mathrm{HI}$.

Titanium, Zirconium, and Hafnium. The sorption order is $\mathrm{Hf}>\mathrm{Zr}>\mathrm{Ti}$, sorption being strongest from $\mathrm{HCl}$ and weakest from $\mathrm{HI}$.

Vanadium, Niobium, and Tantalum. Vanadium, reduced to $\mathrm{V}^{\mathrm{s}+}$ by $\mathrm{HBr}$ and $\mathrm{HI}$ in the presence of resin, is not sorbed from these media. Sorption of $\mathrm{V}^{\mathrm{s}+}$ from $\mathrm{HCl}$ starts at about $8 \mathrm{M}$ and increases to nearly $100 \%$ at $12 \mathrm{M}$.

Niobium, tested only at tracer levels, is sorbed considerably more from $\mathrm{HBr}$ than from $\mathrm{HI}$, with nearly $100 \%$ sorption from $8.7 \mathrm{M} \mathrm{HBr}$, as from $9 M$ $\mathrm{HCl}$.

Tantalum, highly insoluble in both media, was not evaluated.

Chromium, Molybdenum, and Tungsten. Slight sorption of $\mathrm{Cr}^{2+}$ occurs from $\mathrm{HI}$ and $\mathrm{HCl}$, and moderate sorption occurs from $0.1 \mathrm{MBr}$. Chromium(VI), strongly sorbed from $\mathrm{HCl}$, is reduced to $\mathrm{Cr}^{2+}$ by $\mathrm{HBr}$ and $\mathrm{HI}$.

Molybdenum, added as $\mathrm{Mo}^{\mathrm{a}+}$, is sorbed completely from strong $\mathrm{HBr}$, as fron: $\mathrm{HCl}$. Reduction of $\mathrm{Mo}^{\circ+}$, evidenced by developmeni of a blue color, probably explains the low sorption from $\mathrm{HI}$.

Tungsten, highly insoluble in acid rnedia, was not tested.

Technetium, Manganess, and Rhenium. Technetium, tested at the $0.01 \mathrm{M}$ level initially as $\mathrm{Tc}^{7+}$, is sorbed strongly from $\mathrm{HBr}$, as from $\mathrm{HCl}$. Reduction to nonsorbing oxidation states occurs in HI.

Sorption of manganese, greater from $\mathrm{HBr}$ than from $\mathrm{HCl}$, increases with increasing acidity. Sorption of rhenium, on the other hand, decreases with increasing acidity. This trend and the rhenium sorption order of $\mathrm{HCl}>\mathrm{HBr}>\mathrm{HI}$ may be dine to its reduction by the latter two media.

Iron, Cobalt, and Nickel. Sorption of iron from $\mathrm{HBr}$, as from $\mathrm{HCl}$, approaches $100 \%$ with increasing acidity. Sorption of cobalt from $\mathrm{HBr}$ and $\mathrm{HI}$ approaches $100 \%$ at high acidity, compared to about $70 \%$ from $\mathrm{HCl}$. Sorption of iron, reduced to $\mathrm{Fe}^{2+}$ by 


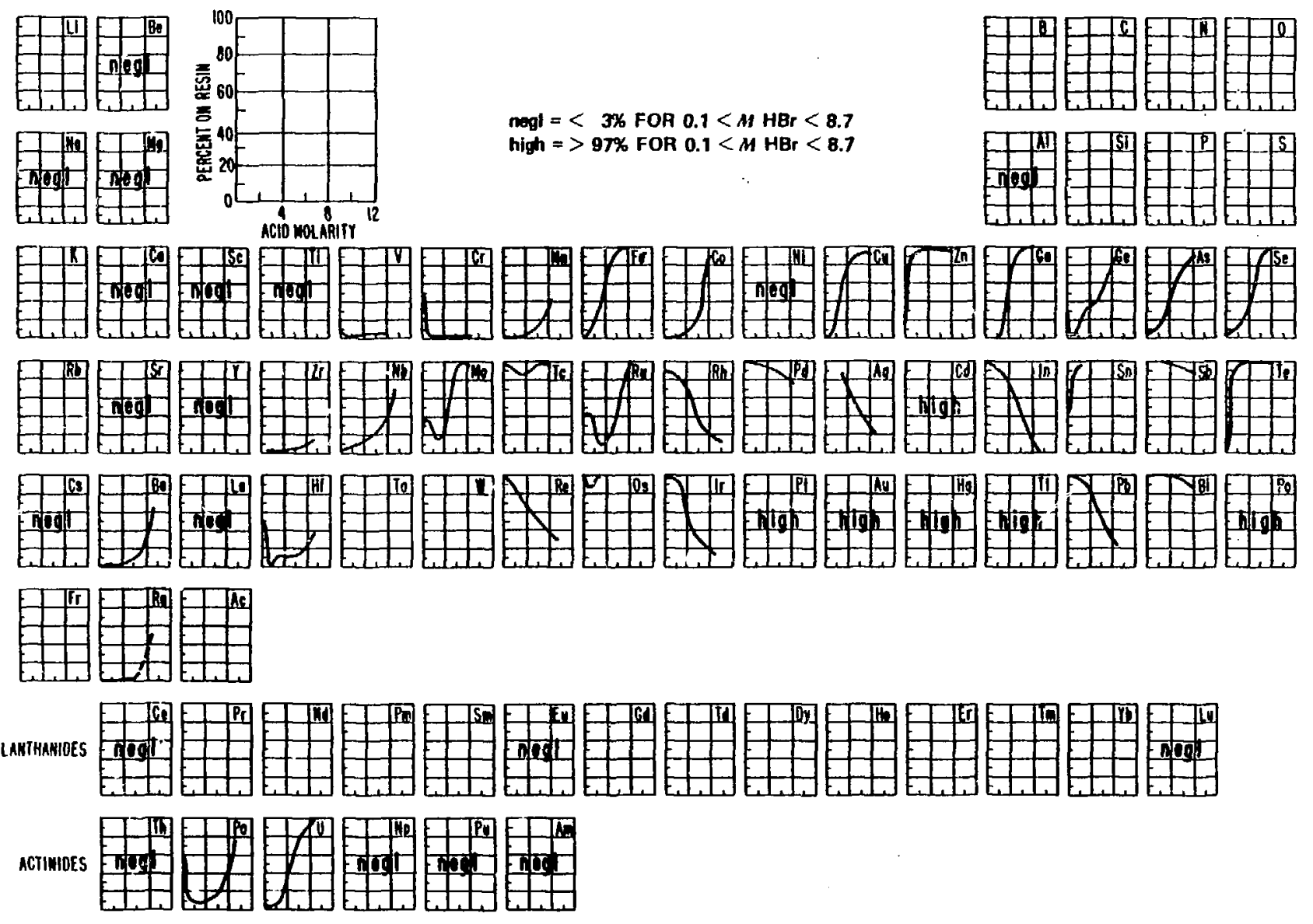

Fig. 1.

Sorption of elements by $1 \times 8$ anion exchange resin from hydrobromic acid (acid volume/resin weight $=10$ ). 

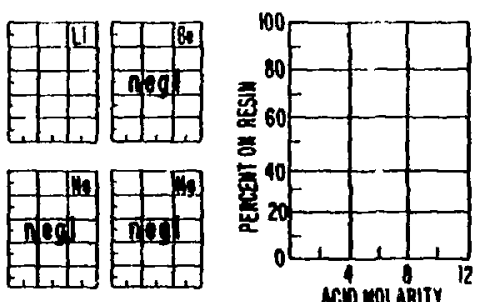

negl $x<3 \%$ FOR $0.1<M$ HBr $<8.7$

high $=>97 \%$ FOR $0.1<M \mathrm{HEr}<8.7$

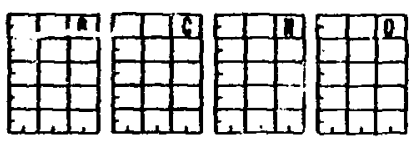

MCD molaritY

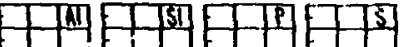

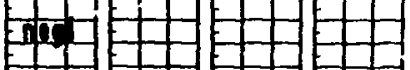

En F+口 En Et:

ᄂамнамиос Acimos

Fig. 2.

Sorption of elements by $1 \times 4$ anion exchange resin from hydrobromic acid (acid valume/resin weight $=10$ ). 

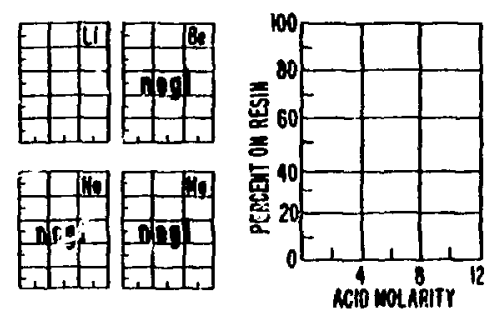

nedl $=<3 \%$ FOR $0.1<M H B r<8.7$

hinh $*>97 \%$ FOR $0.1<M \mathrm{HBr}<8.7$
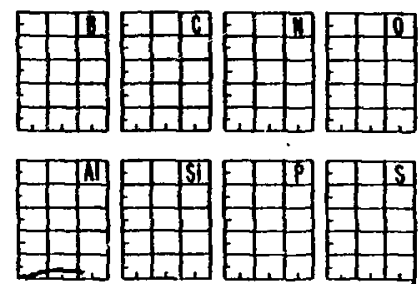

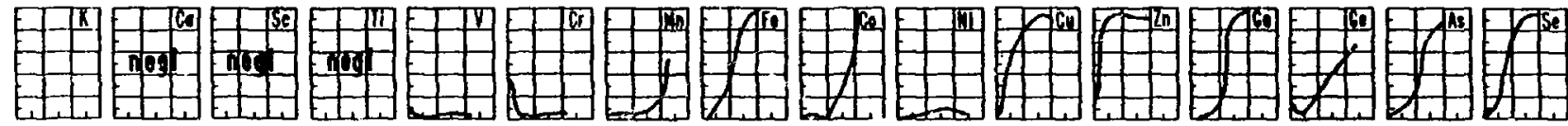

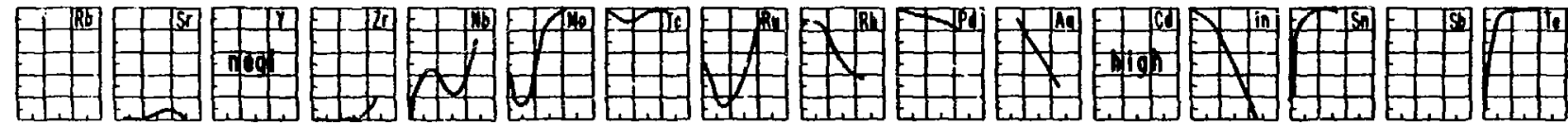

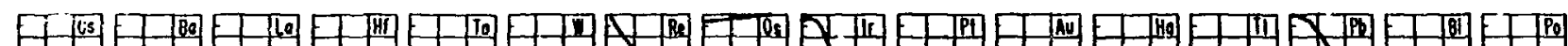

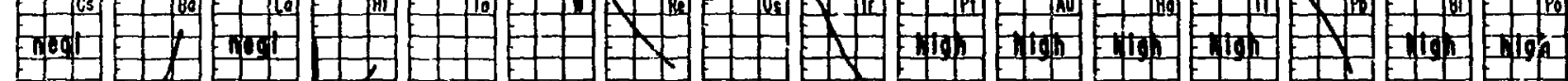

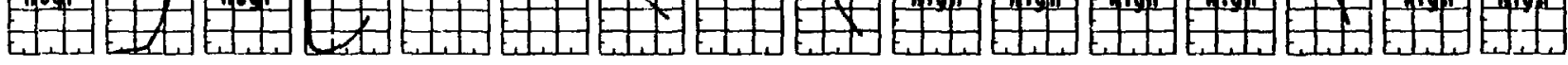

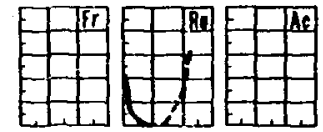

Lamrнnios

ACrinios

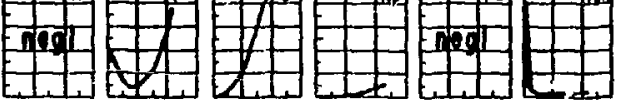

Fig. 3.

Sorption of elcments by MP1 (macroporous) anion exchange resin from hydrobromic acid (acid volume/resin weight $=10$ ). 


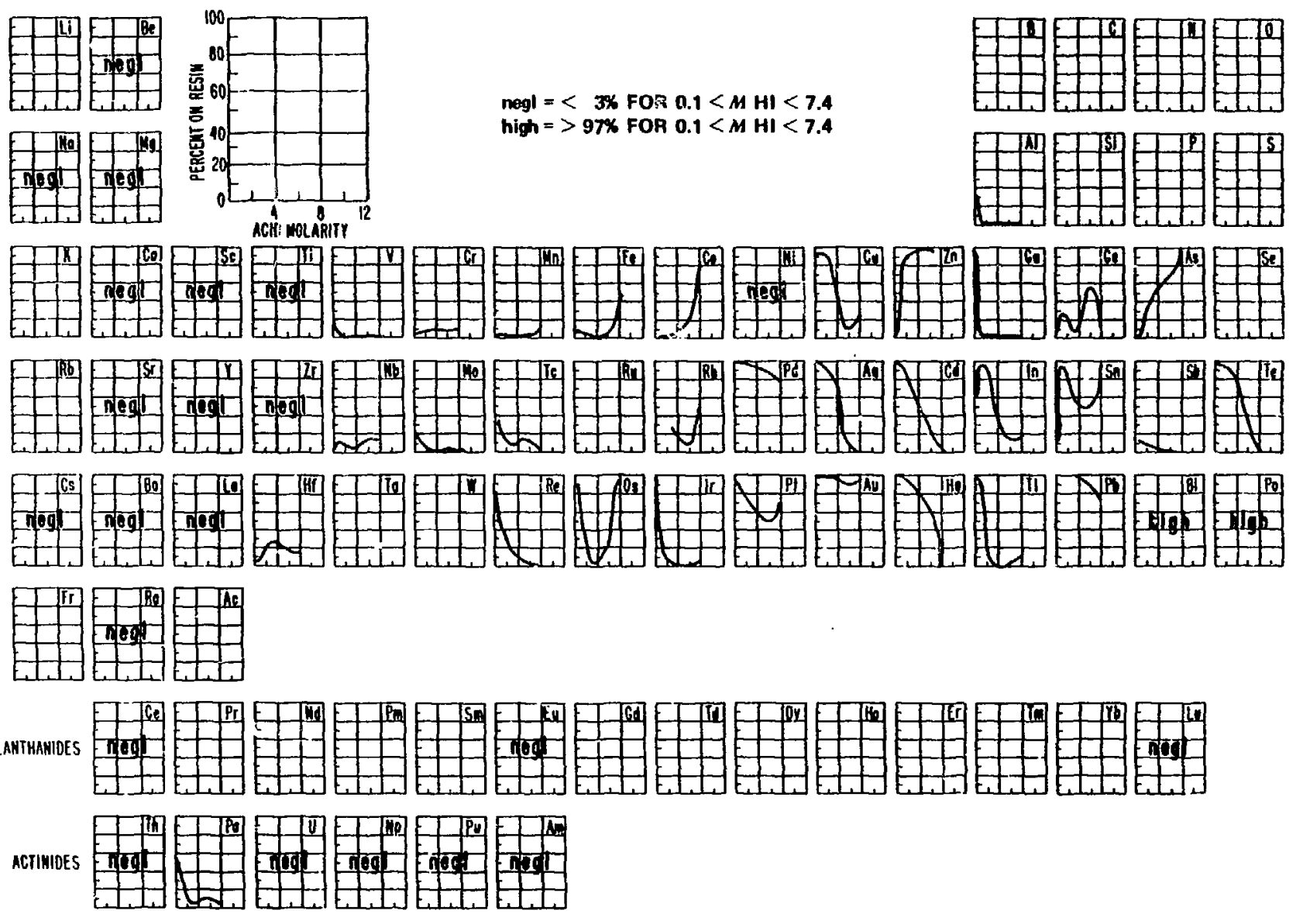

Fig. 4.

Sorption of elements by $1 \times 8$ anion exchange resin from hydriodic acid (acid volume/resin weight $=10$ ). 

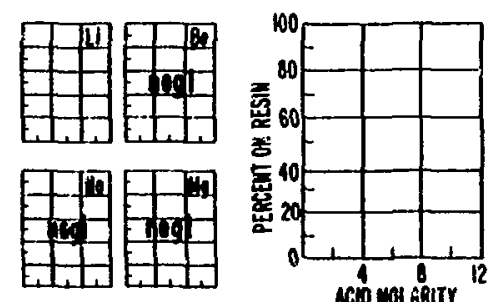

nogl $=<3 \%$ FOR $0.1<M H I<7.4$

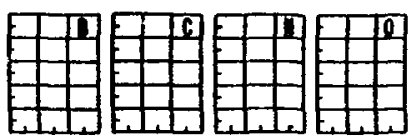

high $=>$ 97\% FOR $0.1<M$ HI $<7.4$

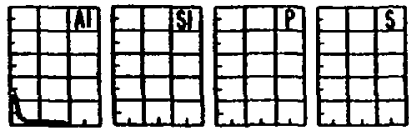

其国
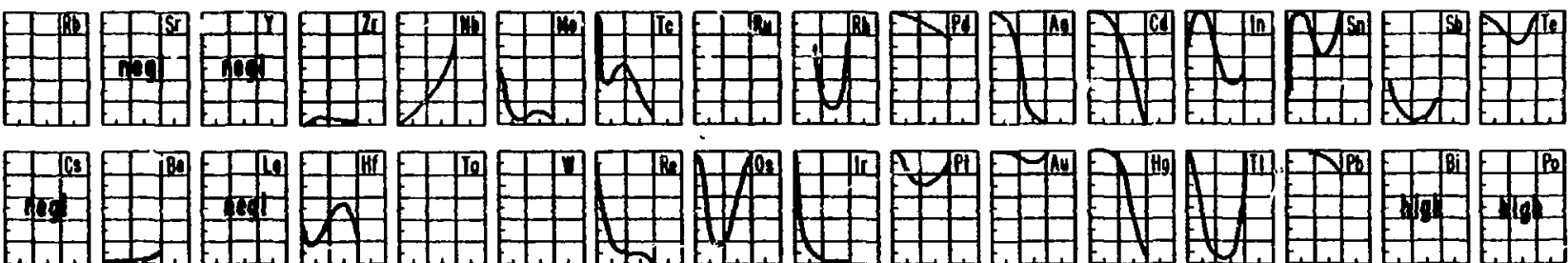

:HAF

Lантинов

Actinios

120

Fig. 5.

Sorption of elements by $1 \times 4$ anion exchange resin from hydriodic acid (acid volume/resin weight $=10$ ). 


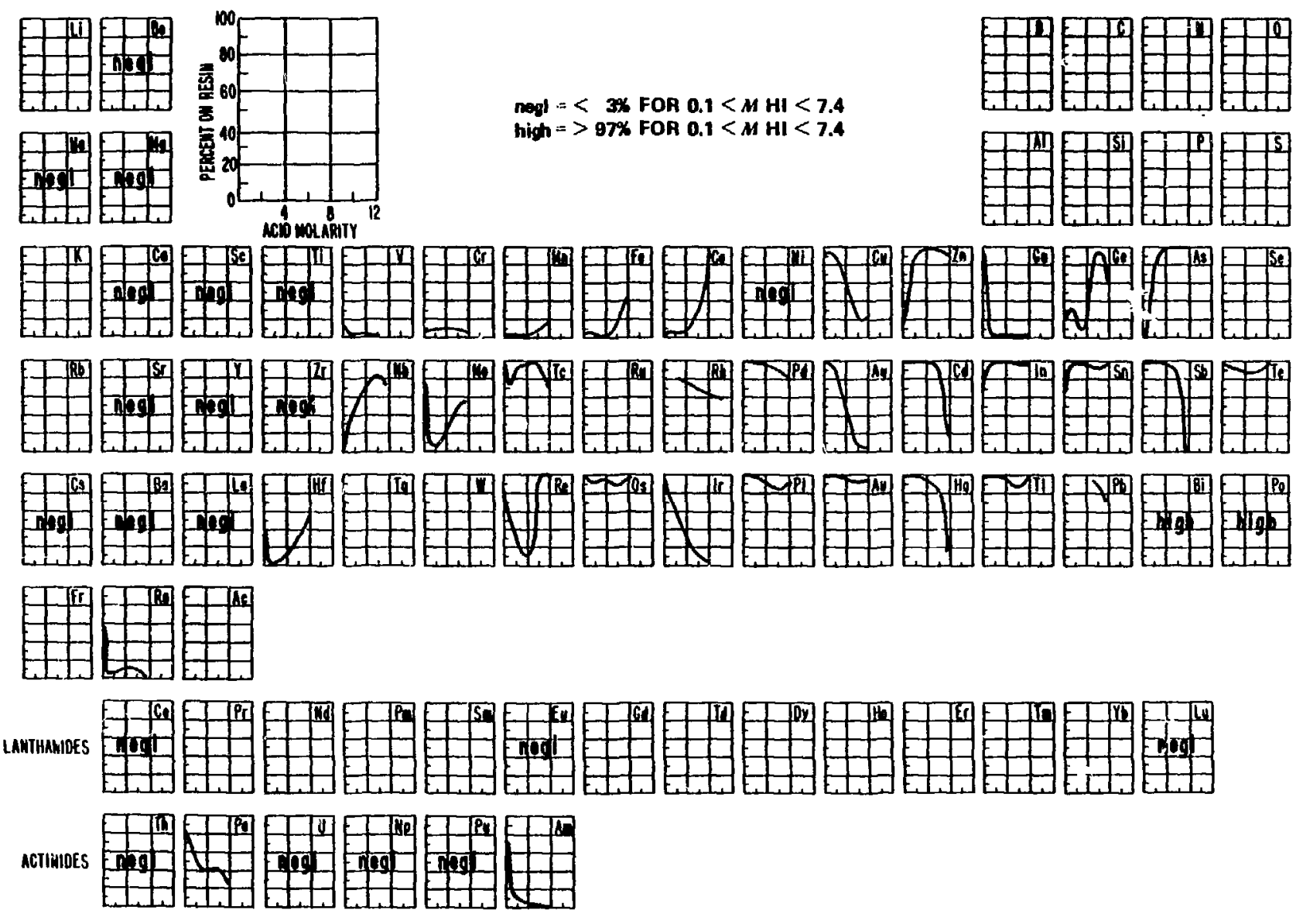

kig. 6.

Sorption of elements by MP1 (macroporous) anion exchanye resin from hydriodic acid (acid volume/resin weight $=10)$. 


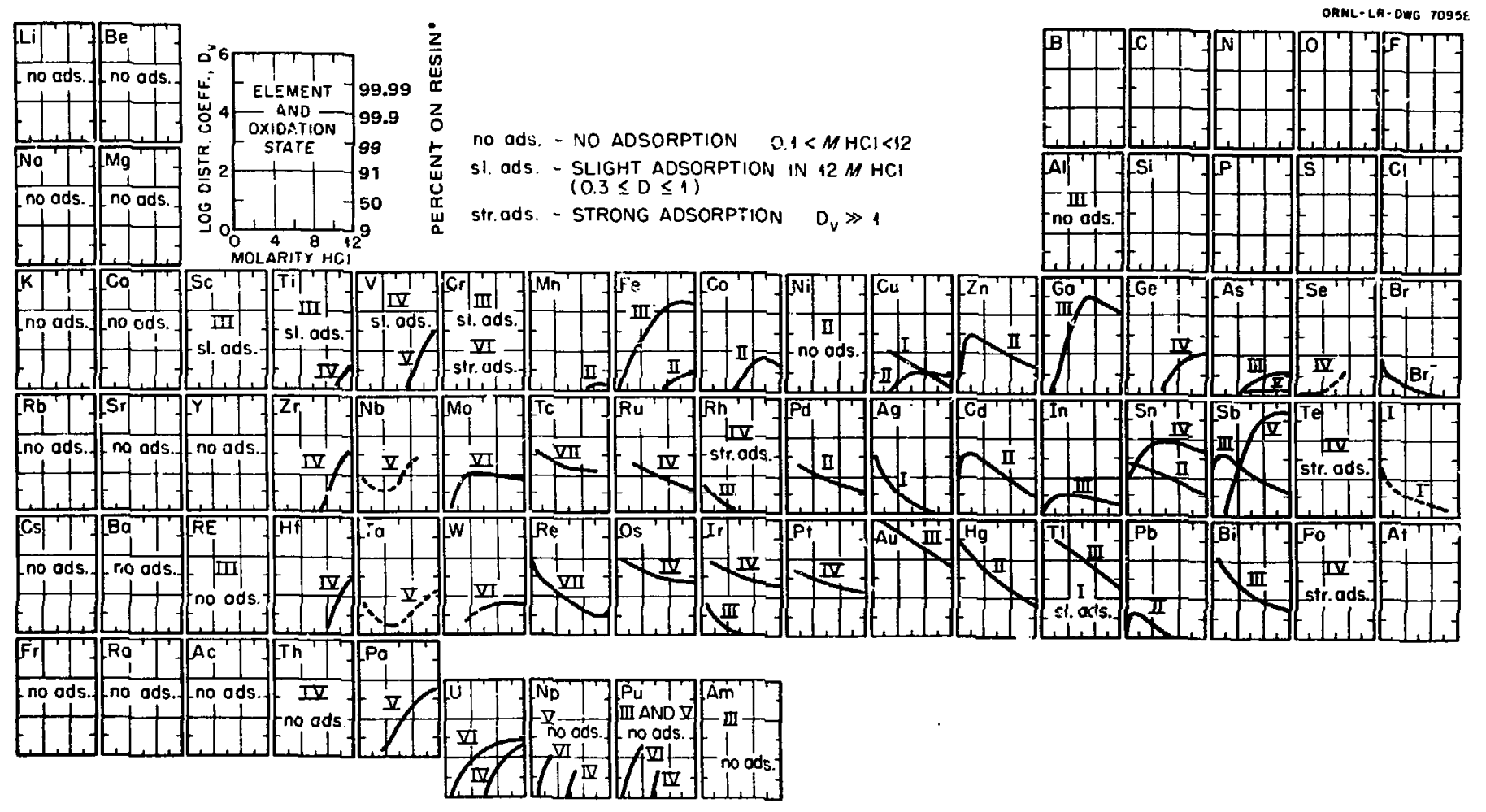

Fig. 7.

Adsorption of elements from $\mathrm{HCl}$ solutions by an anion exchange resin (supplied by $\mathrm{F}$. Nelson). "Percent on resin" scsle added to facilitate comparizon with Fige. 1-6. 
HI, increases with increasing acidity, like that from $\mathrm{HCl}$. Nickel is not sorbed from any of the three acids.

Ruthenium and Osmium. Ruthenium, insoluble in HI, was not tested in it. Sorption of ruthenium, expected to be $\mathrm{Ru}^{9+}$ in $\mathrm{HBr}$, is minimal at $3-4 M$, then approaches $100 \%$ at $8 M$. I his behavior differs from that in $\mathrm{HCl}$ media from which sorption of ruthenium, identified as $\mathrm{Ru}^{4+}$, continuously decreases with increasing acidity.

Osmium, probably as $\mathrm{Os}^{4+}$ (or higher oxidation states) is sorbed strongly from all $\mathrm{HBr}$ levels. Osmium, as $\mathrm{Os}^{\mathrm{s}+}$, is sorbed strongly from all $\mathrm{HCl}$ levels. Osmium, reduced to $\mathrm{Os}^{2+}$ by $\mathrm{HI}$, partially precipitated as $\mathrm{OsI}_{2}$. The filtrates, containing osmium at saturation levels $<0.01 M$, were tested. Sorption from $H I$ is least at 3 to $4 M$, then approaches $100 \%$ with increasing acidity.

Rhodium and Iridium. Because rhodium is insoluble in 0.1 and $1 M \mathrm{HI}$, no data were obtainable at these levels. The oxidation state of rhodium in both $\mathrm{HBr}$ and $\mathrm{HI}$ is no higher than +3 , perhaps +2 in $\mathrm{HI}$. The rhodium pattern of decreasing sorption with increasing $\mathrm{HBr}$ acidity is similar to that of $\mathrm{Rh}^{\mathrm{s}+}$ in $\mathrm{HCl}$. Rhodium is surbed partially from 3-7.4M HI.

The pattern of decreasing iridium sorption with increasing $\mathrm{HBr}$ acidity is more like that of $\mathrm{Ir}^{3+}$ than of $\mathrm{Ir}^{4+}$ in $\mathrm{HCl}$. Iridium, reduced to $\mathrm{Ir}^{2+}$ by iodide, is sorbed appreciably only from $0.1 M \mathrm{HI}$.

Palladium and Platinum. Palladium, as $\mathbf{P d}^{2+}$, approaches $100 \%$ sorption from all three media at low acidity. Sorption decreases with increasing acidity.

Sorption of platinum, as $\mathrm{Pt}^{4+}$, is essentially complete from 0.1-8.7 $\mathrm{M} \mathrm{HBr}$, like that from $\mathrm{HCl}$. Sorption of platinum from $\mathrm{HI}$, in which it should reduce to $\mathrm{Pt}^{2+}$, decreases with increasing acidity to a minimum of $50 \%$ from $6 M \mathrm{HI}$, then slightly increases in stronger acid.

Copper, Silver, and Gold. Sorption of copper, as $\mathrm{Cu}^{2+}$, is higher from $\mathrm{HBr}$ than from $\mathrm{HCl}$. It increases with increasing $\mathrm{HBr}$ conceniration to $>90 \%$ at $6 \mathrm{M}$. Copper behavior in $\mathrm{HI}$, in which it is $\mathrm{Cu}^{+}$, is like that of $\mathrm{Cu}^{+}$in $\mathrm{HCl}$. Sorption is $290 \% \mathrm{a}$. low acidity and decreases with increasing acidity.
No data were obtainable for silver from 0.1 and $1 M \mathrm{HBr}$ and $0.1 M \mathrm{HI}$, in which it precipitated. At higher acid concentrations, silver behaved similarly in all three media; sorption, high at low acidity, decreases with increasing acidity.

Gold, as $\mathrm{Au}^{3+}$, is sorbed strongly from both $\mathrm{HCl}$ and $\mathrm{HBr}$ over the complete acidity range. It also is sorbed strongly, as $\mathrm{Au}^{+}$, from $\mathrm{HI}$.

Zinc, Cadmium, and Mercury. Zinc is sorbed strongly from all three media above $1 M$. Sorptions are strongest from $\mathrm{HBr}$ and $\mathrm{HI}$.

Cadmium approaches $100 \%$ sorption from $\mathrm{HBr}$ up to about $9 M$, whereas its sorption from $\mathrm{HCl}$ decreases with increasing acidity to $<90 \%$ at $9 M$. Its sorption from HI decreases rapidly from nearly $100 \%$ at low acidity to zero at $7.4 \mathrm{M}$.

Mercury, as $\mathrm{Hg}^{2+}$, is sorbed more strongly from $\mathrm{HBr}$ than from $\mathrm{HCl}$. Its sorption as $\mathrm{Hg}^{+}$from $\mathrm{HI}$ decreases rapidly with increasing acidity.

Aluminum, Gallium, Indium, and Thallium. Surprisingly, aluminum is about $30 \%$ sorbed from $0.1 M \mathrm{HI}$, but it is not significantly sorbed from the other two media.

Gallium sorption from $\mathrm{HCl}$ and $\mathrm{HBr}$ approaches completeness with increasing acidity, whereas gallium is not sorbed from HI.

The sorption pattern of indium, as $\mathrm{In}^{3+}$, is similar from $\mathrm{HBr}$ and $\mathrm{HI}$, decreasing from nearly $100 \%$ at low acidity to essentially zero at high acidity. From $\mathrm{HCl}$, the pattern of low sorption at low acidity, in creasing to about $50 \%$ maximum at $3 M$, is different.

Thallium, as $\mathrm{Tl}^{\mathrm{s}}$, is sorbed strongly from both $\mathrm{HBr}$ and $\mathrm{HCl}$. Sorption of thallium, reduced to $\mathrm{Tl}^{+}$, from $\mathrm{HI}$ decreases rapidly from nearly $100 \%$ at low acidity to zero at $3 M$.

Germanium, Tin, and Lead. Germanium precipitated in $\mathrm{HBr}$ and $\mathrm{HI}$. We tested the filtrates containing gurmanium at saturation levels $<0.01 M$. Germanium sorption is similar from $\mathrm{HBr}$ and $\mathrm{HCl}$, increasin:; with increasing acidity to $>90 \%$ at high acidity. Two maxima are obtained in $\mathrm{HI}$, about $15 \%$ sorption at $1-2 M$ and about $50 \%$ at $6 M$.

Sorption of tin, as $\mathrm{Sn}^{4+}$, is nearly $100 \%$ from $\mathrm{HBr}$ and $\mathrm{HCl}$ above about $1 M$. Tin precipitated at the higher HI concentrations, and we tested the filtrates. Tin sorption shows a minimum of abcut 
$50 \%$ from $5-6 M \mathrm{HI}$, but is essentially complete from $<1$ and $7.4 \mathrm{Ni}$

Lead, very ..ssoluble in dilute $\mathrm{HI}$, was not tested at 0.1 and $1 M$. At the higher $\mathrm{HI}$ levels and all $\mathrm{HBr}$ levels, we tested lead at $101 M$ rather than the usual $0.01 \mathrm{M}$. The sorption order from the three media is $\mathrm{HI}>\mathrm{HBr}>\mathrm{HCl}$, with sorption decreasing as acidity increases. Nearly $100 \%$ sorption occurs from <3M $\mathrm{HBr}$ and $\mathrm{HI}$.

Arsenic, Antimony, and Bismuth. Sorption of arsenic from both $\mathrm{HBr}$ and $\mathrm{HI}$ approaches completeness with increasing acidity. It is higher than the sorption of $\mathrm{As}^{\mathrm{s}+}$ from $\mathrm{HCl}$. Sorption of $\mathrm{As}^{\mathrm{s}+}$ is much lower from $\mathrm{HCl}$. Arsenic initially was dissolved in $\mathrm{HBr}$ and $\mathrm{HI}$ as $\mathrm{As}_{2} \mathrm{O}_{3}$ and is believed to have remained as $\mathrm{As}^{\mathrm{s}+}$.

Data for antimony from 0.1 and $1 M \mathrm{HBr}$, and $0.1 M \mathrm{HI}$, were not obtainable cwing to its insolubility. Sorption of antimony, as $\mathrm{Sb}^{+\sigma}$, from $\mathrm{HCl}$ and from $\mathrm{HBr}$ differs considerably. Sorption from $\mathrm{HBr}$ is nearly complete at $2 M$, then decreases slightly at $8.7 \mathrm{M}$. From $\mathrm{HCl}$, sorption increases continuously with increasing acidity, from $10 \%$ at $<2 M$ to nearly $100 \%$ above $4 M$. Antimony, reduced to $\mathrm{Sb}^{3+}$ by HI, is sorbed weakly from it.

The sorption order of bismuth as $\mathrm{Bi}^{\mathrm{j}+}$ is $\mathrm{HI}>\mathrm{HBr}$ $>\mathrm{HCl}$. Sorption from all three media is string, especially at low acidity levels.

Selenium, Tellurium, and Polonium. Se'enium, reduced to the metal by $\mathrm{HI}$, could not be tested in it. Its sorption from $\mathrm{HBr}$ approaches completeness at about $6 M$. This is considerably greater sorption than from $\mathrm{HCl}$.

Tellurium was partially reduced to metal by $\mathrm{HI}$. We used the filtrates containing saturated tellurium iodide at $<0.01 M$ to get distribution data. The decreased tellurium sorption with increasing $\mathrm{HI}$ concentration is not understood. Tellurium precipitated increasingly with increasing $\mathrm{HBr}$ concentration; the filtrates were tested. Tellurium is sorbed strongly from $\mathrm{HBr}$, as from $\mathrm{HCl}$, ap. proaching $100 \%$ sorption above about $2 M$.

Tracer levels of polonium were sorbed completely from all concentrations of all three acids.
Actinides. All actinides except protactinium ond americium tracers were evaluated at the $0.01 M$ level.

Thorium is not sorbed from any of the three acids.

Sorption of protactirium is similar from $\mathrm{HCl}$ and $\mathrm{HBr}$, increasing with acidity to $>90 \%$ at about $9 M$. There is no sorption from $\mathrm{HI}$ except that at low acidity which is suspected to be deposition of a hydrolyzed species. Hydrobromic acid produces the same effect.

Uranium, as $\mathrm{U}^{\text {o+ }}$, behaves similarly in $\mathrm{HCl}$ and $\mathrm{HBr}$; sorption increases with increasing acidity to nearly $100 \%$ at about $8 M$. No sorption occurs from $\mathrm{HI}$ even though uranium does not reduce.

Neptunium is not sorbed from $\mathrm{HBr}$ and $\mathrm{HI}$, whereas the +4 and +6 states are sorbed from $>6 M$ $\mathrm{HCl} .{ }^{16}$ The expecter oxidation state of neptunium is +4 in $\mathrm{HBr}$ and $\mathrm{HI}$ in contact with resin. ${ }^{18}$

Plutonium also is not sorbed from $\mathrm{HBr}$ or $\mathrm{HI}$, whereas the +4 and +6 oxidation states are sorbed strongly from $>6 \mathrm{M} \mathrm{HCl} .{ }^{18}$ Hydriodic acid, and $\mathrm{HBr}$ above about $6 M$, reduce plutonium to nonsorbing $\mathrm{Pu}^{3+}$. Apparently there is little formation of negative bromide complexes of plutonium in $<6 \mathrm{M}$ $\mathrm{HBr}$.

Americium, as tracer level $\mathrm{Am}^{2+}$, is not sorbed on I 8 resir, from any of the three acids.

\section{Distribution as a Function of Resin Cross- Linkage}

The porosity of the three resins follows the order MP1 $\gg 1 \times 4>1 \times 8$. Higher porosity facilitates diffusion of ions within resin particles io provide more accessible exchange sites and faster attainment of equilibriuin. Significant differences in distribution as a function of resin cross-linkage are most striking in $\mathrm{HI}$, and virtually absent in $\mathrm{HBr}$. This may be due to the larger radii of anionic iodide complexes. If to, the cross-linkage effect on anion exchange in $\mathrm{HCl}$ should be insignificant.

Molybdenum, technetium, rhenium, osmium, rhodium, iridium, platinum, sadmium, indium, thallium, germanium, tin, arsenic, antimony, tellurium, and carrier-free protactinum show this 
MP1 > $1 \times 4>1 \times 8$ sorption pattern from $\mathrm{HI}$. Carrier-free niobium follows this pattern in both HI and $\mathrm{HBr}$. Aluminum follows the reverse of this pattern in $0.1 M \mathrm{HI}$, where the order of sorption, although low, is $1 \times 8 \simeq 1$ ×4>MP1. Sorption of carrior-free radium on MP1 resin is about $50 \%$ from $0.1 M \mathrm{HBr}$ and $\mathrm{HI}$, but it is near zero from other systems.

The greatest sorption of hafnium from $\mathrm{HI}$ shifts from $3 M$ with 1 × 8 resin to $6 M$ with $1 \times 4$ resin and to $7.4 M$ with MP1 resin.

Tracer-level americium is $>70 \%$ eorbed on MPI regin from $0.1 \mathrm{M} \mathrm{HBr}$ and $\mathrm{HI}$. It is about $30 \%$ sorbed on 1 × 4 resin from $0.1 M \mathrm{HBr}$. The indicated formation of an anionic complex of americium in dilute acid is unexpected and not understood.

\section{Effect of Nonisotople Carrier}

The distribution of an element on ion exchange resin is known to vary as the element concentration changes from tracer to macro levels. Moat of the elements in this study were tested at a $0.01 M$ concentration corresponding to $3-10 \%$ of the total resin capacity. Distribution data for the few elements measured at tracer levels cannot be considered to repre sent their distributions at macro levels. However tracer-based distribution data for elements, such as radium, polonium, and protactinum, unlikely to be present in higher concentrations, are valuable.

The effect of another element having similar chemistry was evaluated using radium with and without $0.01 M$ barium as a nonisotopic carrier. Tracer radium alone, as discussed earlier, is sorbed only from $0.1 M \mathrm{HBr}$ and $0.1 M \mathrm{HI}$ and only on MP1 resin, somewhat like tracer americium. In the presence of $0.01 M$ barium, howeve:, tracer radium follows the barium distribution pattern by increasing rapidly with increasing $\mathrm{HBr}$ molarity above $6 M$. This indicates that barium and radium chemically interchange so that radium follows the unique anion exclaange distribution pattern of lsarium in $\mathrm{HBr}$.

\section{APPLICATIONS}

Anion exchange in $\mathrm{HBr}$ and $\mathrm{HI}$ should provide versatility to the separation chemist. Examples of potentially useful separations, using a single $\mathrm{HBr}$ or HI medium, are given in Table I. Table II presents examples of potentially more selective separations using various combinations of $\mathrm{HCl}, \mathrm{HBr}$, and $\mathrm{HI}$ as the sorption and elution media. These examples, derived from the data presented in Figs. 1-7, have not been tested experimentally. We expect that readers who consider the data for specific appiications will develop other useful separations.

\section{ACKNOWLEDGMENTS}

R. D. Gardner, LASL, provided the atomic absorption measurements of vanadium and rhodium. The general assistance of Mrs. Romayne Ortiz is appreciated. 


\section{POTENTIALLY USEFUL SEFARATIONS INVOLVING A SINGLE HBr OR HI MEDIUM}

\section{Element Sepersted}

$\mathrm{Ba}$

$\mathrm{Zr}$

$\mathrm{Nb}$

$\mathrm{Cr}$

Tc

$\mathrm{Ru}$

Ir

Ir, Re

$\mathrm{Zn}$

$\mathrm{Ga}$

In

$\mathrm{Sb}$

Po

Po

$\mathrm{Pa}$

U

Am
Sepkrated From

\begin{tabular}{|c|c|}
\hline Mediun & Ion Exchange \\
\hline Strong $\mathrm{HBr}$ & $1 \times 4,1 \times 8$ \\
\hline Strong HI & MP1 \\
\hline Strong HI & MP1 \\
\hline $0.1 M \mathrm{HBr}$ & $1 \times 8,1 \times 4$ \\
\hline $4 M \mathrm{HI}$ & MP1 \\
\hline $3 M \mathrm{HBr}$ & $1 \times 8,1 \times 4$, MP1 \\
\hline Strong HI & MP1 \\
\hline Strong HI & $1 \times 4$ \\
\hline Strong HI & $1 \times 8,1 \times 4$ \\
\hline$>2 M \mathrm{HI}$ & MP1 \\
\hline Strong $\mathrm{HBr}$ & $1 \times 8,1 \times 4, M P 1$ \\
\hline Strong HI & $1 \times 8,1 \times 4, M P 1$ \\
\hline Strong HI & $1 \times 8$ \\
\hline $0.1 M \mathrm{HBr}$ & $1 \times 8,1 \times 4$, MP1 \\
\hline Strong $\mathrm{HBr}$ & $1 \times 8$ \\
\hline Strong $\mathrm{HBr}$ & $1 \times 8,1 \times 4$, MP1 \\
\hline $\mathrm{HBr}$ or $\mathrm{HI}, 0.1 \mathrm{M}$ & MP1 \\
\hline
\end{tabular}

\section{TABLE II}

POTENTIALLY USEFUL SEPARATIONS INVOLVING COMBINATIONS OF HCl, HBr, AND HI MEDIA

\begin{tabular}{|c|c|c|c|c|}
\hline $\begin{array}{l}\text { Element } \\
\text { Separated }\end{array}$ & $\begin{array}{l}\text { Separated } \\
\text { From }\end{array}$ & $\begin{array}{l}\text { Sorption } \\
\text { Medium }\end{array}$ & Elutant & Resin \\
\hline Cr & Most Elements & $0.1 M \mathrm{HEr}$ & Strong $\mathrm{HBr}$ & $1 \times 8$ \\
\hline $\mathrm{v}$ & $\begin{array}{l}\mathrm{Cr}, \mathrm{Mn}, \mathrm{Fe}, \mathrm{Co}, \mathrm{Ni}, \\
\mathrm{Cu}, \mathrm{Zr} \text {, and Many } \\
\text { Others }\end{array}$ & Strong $\mathrm{HCl}$ & Strong $\mathrm{HBr}$ & $1 \times 8$ \\
\hline $\mathrm{Sb}, \mathrm{As}, \mathrm{Bi}$ & Each Sequentislly & $\begin{array}{l}\text { 3trcng HI } \\
\text { (Sb Elutes) }\end{array}$ & $\begin{array}{l}0.1 M \text { HI } \\
\text { (As Elutes) }\end{array}$ & $1 \times 8$ \\
\hline $\mathrm{Ga}$ & Most Elerzents & $0.1 M \mathrm{HI}$ & $0.1 M \mathrm{HBr}$ & MP1 \\
\hline $\mathrm{Te}$ & Moat Eledients & $\begin{array}{l}\text { Strong HI } \\
\text { Followed By } \\
0.1 M \text { HI }\end{array}$ & $0.1 M \mathrm{HBr}$ & MP1 \\
\hline $\mathrm{Pb}$ & $\begin{array}{l}\text { Most Elements } \\
\text { Except Noble } \\
\text { Metals and Cr }\end{array}$ & $0.1 M \mathrm{HBr}$ & Strong $\mathrm{HCl}$ & $1 \times 8$ \\
\hline
\end{tabular}




\section{REFERENCES}

1. K. A. Kraus and F. Nelson, "Anion Exchange Studies XXII. IItetal Separations by Anion Exchange," in Am. Soc. Testing Materials, Spec. Tech. Publ. No. 195, (1958), pp. 27-59.

2. J. P. Faris and R. F. Buchanan, "Anion Exchange Characteristics of Elements in Nitric Acid Medium," Anal. Chem. 36, 1157-1158 (1964).

3. J. P. Faris, "Adsorption of the Elements from Hydrofluoric Acid by Anion Exchange," Anal. Chem. 32, 520-522 (1960).

4. P. Van den Winkel, F. De Corte, and J. Hoste, "Distribution Coefficients for 65 Elements in Acetic Acid on Dowex 1x8," J. Radionnal. Chem. 10, 139 143 (1972).

5. H. Polkowska-Motrenko and R. Dybezynski, "Distribution Coefficients of 52 Elements on a Strongly Basic Anion-Exchange Resin in Aqueous Solutions of Orthophosphoric Acid," J. Chromatog. 88, 387-390 (1974).

6. J. Korkisch, "Ion Exchange of Uranium and Thorium in Mixed and Non-Aqueous Solvents, "U. S. Atomic Energy Commission report TW-22402 (October 1965) pp. 93-115.

7. J. M. Peters and G. del Fiore, "Distribution Coefficients for 52 Elements in Hydrochloric AcidWater-Acetone Mixture of Dowex 1E8, " Radiochem. Radioanal. Lett. 21, 11-21 (1975).

8. T. Andersen and A. B. Knutsen, "AnionExchange Study. I. Adsorption of Some Elements in
HBr Solutions. Acta Chem. Scand. 16, 849-854 (1962).

9. E. Klakl and J. Korkisch, "Cation Exchange Behavior of Several Elements in Hydrobromic AcidOrganic Solvent Media," Talanta 16, 1177-1190 (1969).

10. S. F. Marsh, M. R. Ortiz, R. M. Abernathey, and J. E. Rein, "Improved Two-Column Ion Exchange Separation of Plutonium, Uranium, and Neodymium in Mixed Uranium Plutonium Fuels for Burnup Measurement," Los Alamos Scientific Laboratory report LA-5568 (June 1974).

11. W. Rieman and H. F. Walton, Ion Exchange in Analytical Chemistry (Pergamon Press, New York, 1970), p. 61.

12. K. S. Kim, Styrene and Divinylbenzene Copolymer, Ph.D. Dissertation, The City University of New York, 1971, University Microfilms No. 72-13, p. 470 .

13. G. H. Morrison and H. Freiser, Solvent Extraction in Analytical Chemistry (John Wiley \& Sons, New York, 1957), p. 12.

14. W. M. Latimer, The Oxidation States of the Elem ents and Their Potentials in Aqueous Solution, 2nd Ed. (Prentice-Hall Inc., New York, 1952).

15. J. Korkisch, Modern Methods for the Separation of Rarer Metal Ions, (Pergamon Press, New York, 1969) p. 64.

16. F. Nelson and D. C. Michelson, "Ion-Exchange Procedures IX. Cation Exchange in $\mathrm{HBr}$ Solutions," J. Chromatog. 25, 414-441 (1966). 